\title{
Os primórdios do turismo em Macau e Cantão no século XIX: Do território de fronteira ao lugar urbano
}

\author{
The beginnings of tourism in Macau and Canton in the xix ${ }^{\text {th }}$ century: \\ From a border territory to an urban place
}

\author{
Frédéric Vidala
}

Resumo Este texto tem por objetivo apresentar uma reflexão geral sobre os primórdios do processo de transformação de Macau e Cantão em lugares turísticos. Trata-se de um estudo exploratório conduzido a partir da análise de relatos de viajantes ocidentais em Macau e Cantão, entre as décadas de 1830 e de 1870. Observa-se como o uso lúdico ou turístico do espaço urbano contribuiu para a transformação global da percepção dessas cidades que, através dessas práticas, aparecem menos fragmentadas e segregadas. Os primeiros guias turísticos de Cantão e Macau vêm reforçar a ideia de transformação das representações desses territórios de fronteira, que eram até então vistos como uma simples zona de contatos e intercâmbios comerciais entre a China e o Ocidente, em lugares urbanos, inseridos em um circuito turístico internacional e em vias de adquirir dimensão cosmopolita.

Palavras-chave Práticas turísticas, espaço urbano, sociabilidade, Macau, Cantão

Abstract This text aims to present a broad reflection on the beginnings of Macao and Canton transformation process into tourist places. This exploratory study is conducted through an analysis of Western travelers' accounts in Macau and Canton, between the 1830 s and the 1870 . We can observe how recreational or tourist use of urban space contributes to the overall transformation of the perception of these cities that appear, in this context, less fragmented and segregated. The first tour guides on Canton and Macau emphasize the transformation of the representation of these border territories, which were until then seen as a simple zone of contacts and trade exchanges between China and the West. Macau and Canton are then described as urban places, inserted in an international tourist circuit and that have acquired a cosmopolitan dimension.

Keywords Tourist practices, urban space, sociability, Macao, Canton

a Professor auxiliar convidado na Escola de Sociologia e Políticas Públicas do ISCTE-Instituto Universitário de Lisboa. Membro do Centro em Rede de Investigação em Antropologia (CRIA) 


\section{INTRODUÇÃ̃ 1}

Desde o século XVII, Macau e Cantão têm ocupado uma posição singular - e quase exclusiva - nas relações comerciais e políticas, muitas vezes conflituais, entre o Ocidente e a China (Hsü, 1983). Nos meados do século XIX, alguns relatos e correspondências de viajantes europeus e americanos no sul da China descrevem essas cidades como lugares de recreação cujos valores culturais ou estéticos já são reconhecidos. Segundo esses relatos, esses lugares podem ser potencialmente desfrutados por qualquer pessoa curiosa, à procura de novos prazeres e sensações. A transformação na perceção e descrição de Macau e Cantão pode ser entendida como o resultado de uma lenta evolução das experiências dos viajantes. Esta evolução manifesta-se tanto nas descrições dos lugares visitados e percorridos (as representações) como nas próprias vivências dos viajantes (as práticas).

A historiografia do turismo deu pouca atenção à grande diversidade das práticas turísticas, ou seja, nas maneiras de ser turista (Spode, 2010). O turista raramente foi visto como um ator social cujas escolhas e experiências poderiam ter influenciado a evolução do fenômeno turístico na sua globalidade. Neste ponto de vista, os historiadores ficaram muitas vezes reféns das categorias de pensamento e percepção que emergiram com a difusão das práticas turísticas durante a primeira metade do século XIX. A partir da década de 1830, na Europa, a palavra "turista" designa um indivíduo singular, com uma fama duvidosa. A palavra é associada à ideia de ausência de personalidade ou de gosto pessoal. O turista é descrito antes de mais nada como um mau viajante (Urbain, 2002). Do ponto de vista dos contemporâneos, o turismo ganha rapidamente um interesse econômico - a expressão "indústria do turismo" surge no final do século XIX - ou educativo, mas é geralmente entendido como um fenômeno cultural e econômico global que parece encontrar na massificação dos anos 1950 e 1960 o seu termo natural.

Falar de "práticas turísticas" (no plural) pressupõe um outro tipo de abordagem. No seu livro sobre os primórdios do fenômeno turístico na Europa do final do século XIX, Catherine Bertho-Lavenir (1999) argumenta que a "invenção" das "práticas turísticas" foi um processo de longa-duração (cerca de um século), associando a transformação das representações e percepções do ambiente (natural ou urbano) e as mutações culturais e técnicas. Este estudo interliga duas dimensões

1 Este estudo foi previamente apresentado no III Colóquio Internacional Interdisciplinar Literatura, viagens e turismo cultural no Brasil, em França e em Portugal (Faculdade de Letras da Universidade de Lisboa, 2015). Agradeço aos organizadores do colóquio a autorização para publicação na Revista Plural. As traduções para o português dos textos citados são de minha autoria. 
essenciais da história do turismo: por um lado, a dimensão cultural, afetiva ou sensorial (as percepções) e, por outro lado, a dimensão social e material (os usos dos lugares). Convido a pensar a história das práticas turísticas nos cruzamentos entre essas dimensões, estando atento, por um lado, à maneira como os atores sociais descrevem ou narram as suas experiências, mas também, por outro, aos usos do espaço que podem estar na origem de uma transformação física do território, nomeadamente em contexto urbano.

No estudo que aqui apresento, "viagem" e "turismo" não designam categorias estanques, mas sim um conjunto de práticas, atitudes, posições, experiências, mais ou menos individualizadas ou estandardizadas, e que conhecem no período em estudo profundas evoluções, num contexto global da difusão de um turismo internacional, materializado pela publicação de guias turísticos sobre a China durante a segunda metade do século XIX. A partir do caso de Macau e Cantão, interessa-me sobretudo analisar a relação entre turismo e cidade (Cocks, 2001). Esta relação pode ser analisada a partir das mudanças físicas ou materiais que afetaram os espaços urbanos ou em via de urbanização - construção de estradas, hotéis, casinos, promenades (calçadas) - mas também a partir da transformação dos usos ou práticas, o que podemos chamar o grau de "urbanidade" - as sociabilidades, as práticas da promenade, a visita, os lazeres, a vida cultural (Sтоск \& LUCAS, 2012).

Não pretendo, todavia, evidenciar a transformação global de territórios que, com o desenvolvimento progressivo e sempre limitado do turismo, teriam conhecido uma forma de "ocidentalização". Proponho aqui apresentar sumariamente relatos de situações ou práticas que emergem e são inteligíveis num contexto local. São dinâmicas sociais ou pequenos eventos que podem ter uma importância ou consequências limitadas mas que, considerados numa longa duração, ilustram o papel da viagem e do turismo na transformação da perceção e dos usos do espaço urbano. Ou seja, o turismo é aqui considerado como um modo de habitar a cidade - isto é, relacionar-se socialmente e afetivamente com os lugares urbanos - que se torna cada vez mais comum na época em estudo e que não se limita a situações claramente identificadas como turísticas (LuSSAULT, 2007).

Este texto tem um carácter exploratório. Os relatos evocados aqui referem-se a contextos sociais e culturais complexos e instáveis, num momento histórico particularmente conturbado para a China e o mundo urbano chinês (HENRIOT, 1996). A escolha de um arco temporal relativamente alargado faz correr o risco da aproximação entre situações e práticas com significados bastante díspares. No entanto, é este confronto entre experiências e representações relativamente 
distantes no tempo que deixa emergir a transformação das percepções e dos usos dos lugares percorridos ou visitados pelos viajantes e turistas.

\section{A REPARTIÇÃO DAS FUNÇÕES: TRABALHO E PRAZERES (1820-1830)}

Como ponto de partida deste estudo, escolhi uma notícia publicada em abril de 1836 no Canton Register, primeiro periódico de língua inglesa difundido na China. Trata-se da carta de um leitor que elogia as qualidades e a doçura da vida em Macau, convidando os "amigos" comerciantes e homens de negócios de Cantão a gozar um pequeno período de "férias das suas incessantes obrigações profissionais".

O negócio tem de ser cuidado, senão o negócio não cuida de nós: um antigo e excelente adágio. No entanto, não pode ser inaceitável para os nossos amigos no Cantão ficarem a conhecer as circunstâncias que podem conduzir a umas pequenas férias dos seus incessantes passatempos, assim como o belíssimo ar de Macau, e atrevo-me a ter esperança que o Senhor permita que a informação seja transmitida nas vossas colunas (The Canton Register, 19 April 1836). ${ }^{2}$

Depois deste convite geral, essa carta faz uma descrição detalhada dos últimos eventos sociais em Macau, nomeadamente uma representação de teatro. Este retrato da vida social de Macau nos anos 1830 pode ser considerado como mais um testemunho da imagem da Macau oitocentista como "cidade de todos os prazeres" (Oliveira, 2000, p. 432). A partir de 1827, os números do Canton Register evocam com grande regularidade as corridas de cavalos, regatas e outros eventos sociais organizados em Macau. Nos anos que antecederam a primeira Guerra do Ópio (1839-1842), a imprensa de língua inglesa acompanhou a difusão de uma sociabilidade de recreação, que se desdobrou em encontros, salões, serões culturais e de jogo, frequentados pelas comunidades britânica e americana (PUGA, 2007; VAN DYKe, 2012).

Mas o que chama a atenção nesta carta de abril de 1836 é também a ideia de promoção de Macau enquanto lugar de descanso, lazeres e entretenimento. $\mathrm{O}$ cosmopolitismo do velho porto português é potencializado pelo clima de convívio entre "convidados" e "anfitriões" que faz esquecer os episódios de tensão que marcaram a vida de Macau e as relações luso-britânicas no início do século.

2 "Business must be attended to, or business will not attend to us: an old and excellent adage. I may not, however, be unacceptable to our friends in Canton to be made acquainted with circumstances which may induce a little holiday from their unceasing avocations, in addition to the fine air of Macao, and I venture to hope you will permit the information to come through your columns". 
À chegada das senhoras, oficiais militares e outros senhores portugueses estavam presentes para conduzi-las às suas cadeiras entre os vários atos. Foi servido chá a toda a comitiva e, numa palavra, a generosa atenção dos nossos portugueses para conosco, estrangeiros, foi muito gratificante; tanto militares como civis pareciam muito desejosos por contribuir para a diversão de todos; e é uma enorme vantagem que vivamos sob os auspícios de um governador tão estimado como Sua Excelência Bernardo José de Souza Soares de Andrea, a quem somos, é claro, muito gratos pela promoção da real e amigável relação entre os nativos de Portugal e da Grã-Bretanha, que quanto mais cultivada for, mais felizes seremos... (The Canton Register, 19 April 1836). ${ }^{3}$

Esta atmosfera nova, provavelmente bastante idealizada, é aqui claramente utilizada como argumento de valorização e de promoção de Macau para os comerciantes ocidentais residentes em Cantão. Existe uma repartição original do tempo e das funções entre as duas cidades então frequentadas pelos ocidentais: o trabalho e o comércio nas "feitorias" de Cantão, as férias e o descanso em Macau.

Nesses territórios, as práticas de lazer vêm intrometer-se numa longa história de contatos e intercâmbios, muitas vezes conflituais, sobretudo no século XIX, entre o mundo chinês e os estrangeiros ocidentais. Falar de "estrangeiro" ou de "ocidental" é no entanto bastante impreciso: os estatutos e as funções (comerciante, missionário, membros das grandes companhias comerciais), as condições de nacionalidade ou de gênero determinam muitas vezes a forma da presença na cidade, os usos, os direitos, as obrigações e proibições. Entre 1757 e a primeira Guerra do Ópio, Cantão foi o único porto chinês aberto aos comerciantes estrangeiros (Hsü, 1983, p. 139-167; VAN DyKe, 2012). Fora das muralhas da cidade, desenvolveu-se um espaço comercial - as factories - onde residia durante parte do ano uma comunidade de comerciantes colocados sob o controle da administração chinesa. As atividades comerciais, mas também a vida cotidiana dos ocidentais em Cantão, eram reguladas por um código bastante estrito que procurava limitar os contatos entre estrangeiros e chineses ao estrito mínimo requerido pelos intercâmbios comerciais. No início do século XIX, era assim proibido aos estrangeiros perma-

3 "On the arrival of the ladies, military officers and other Portuguese gentlemen were in attendance to conduct them to their chairs between the several acts. Tea was handed round to all the company; and, in a word, the Kind attention of our Portuguese to us foreigners was most gratifying; both military and civilians seemed most desirous to contribute to the amusement of all; and it is a most valuable advantage that we live under the auspices of such an esteemed governor as His Excellency Bernardo Jose de Souza Soares de Andrea, to whom we are, of course, so much indebted for the promotion of that real and friendly intercourse between the natives of Portugal and Great Britain, which the more it is cultivated the happier we shall be...”. 
necer em Cantão fora da época comercial, circular fora das feitorias, comprar livros chineses ou aprender a língua chinesa. Igualmente, as mulheres ocidentais não podiam permanecer em Cantão (EDWARDs, 1977).

Até 1842, esses estrangeiros eram colocados à margem da comunidade urbana: espacialmente - fora das muralhas - mas também social ou culturalmente. No entanto, os testemunhos sobre a vida cotidiana em Cantão durante as primeiras décadas do século XIX, não são todos idênticos. Se alguns evocam o clima de tensão com as autoridades chinesas, outros falam também do exotismo e da doçura das estadias no sul da China. A diferença de experiências e as conjunturas políticas podem justificar essas variações nas percepções (Morse, 1966). Mas à medida que o "Canton system" cresceu, a própria organização dos espaços nas feitorias transformou-se. Ao lado dos armazéns e das habitações sumárias, surgem algumas ruas bastantes animadas com bares e restaurantes (Downs, 2014).

A evolução do papel de Macau no sistema urbano do sul da China inscreve-se neste contexto social, político e jurídico. Durante as primeiras décadas do século XIX, esta intensa atividade comercial em Cantão tem consequências na vida cotidiana de Macau, onde a maior parte dessas regras não se aplica. A diferença de tratamento é particularmente visível através da presença das mulheres estrangeiras na sociedade macaense, como enfatizado no artigo do Canton Register de 1836.

\section{LIMITES E FRONTEIRAS EM CIDADES FRAGMENTADAS (1830-1840)}

Nos anos que antecederam a primeira Guerra do Ópio e a chegada do governador João Ferreira do Amaral, Macau era de fato frequentemente descrita pelos ocidentais como um espaço fragmentado e segregado, onde as condições de vida e de higiene delimitam fronteiras sociais rígidas entre as populações (OLIVEIRA, 2000). Essa perceção corresponde a um modelo comum a muitas cidades da Ásia que se desenvolveram na época contemporânea num contexto colonial (BickERs, 1998; HENRIOT E Zu'An, 2002). A presença de visitantes ou de viajantes nesses espaços vem sublinhar e reforçar essas tensões espaciais, mas pode também reconfigurá-las.

Dois jornais de viagem são particularmente úteis para reconstituir as representações do espaço urbano em Macau e Cantão no segundo quarto do século XIX. O primeiro é o diário escrito por Harriette Low, uma jovem americana de Salem (Massachusetts) que fez uma longa estadia em Macau, entre 1829 e $1834^{4}$. Embarcou para a China para fazer companhia à sua tia Abigail Knapp Low, que se

4 Aqui, utilizo a versão do jornal de Harriett Low editada por Nan P. Hodges e Arthur W. Hummel (2002). 
estabeleceu em Macau enquanto o seu marido, William Henry Low, era responsável pelos negócios da companhia Russell \& Co. em Cantão. O diário de Harriett Low é um documento cativante e, como já vários autores o assinalaram, uma fonte riquíssima para a história social e cultural em Macau nos anos que antecedem a primeira Guerra do Ópio e que marcam o apogeu do "Canton system" (PugA, 2008; LAMAS, 2006). No seu diário, Harriett Low descreve longamente a sua vida cotidiana ritmada pelas práticas religiosas, as pequenas festas, os encontros sociais, as leituras e conversas, etc. Queixa-se do tédio da sociedade macaense: uma sociedade tipicamente colonial, fechada sobre si mesma. No momento da sua chegada a Macau, a jovem Harriett Low não esconde o seu desejo de procurar prazeres e divertimentos, em primeiro lugar no espaço privado das pequenas comunidades dos americanos.

Macau vista do mar é linda, com alguns pontos muito românticos. Chegamos lá cerca das dez horas, pegamos nas cadeiras sedan e fomos para nossa casa, de cuja aparência gostamos muito. As ruas de Macau são estreitas e irregulares, mas temos um jardim no qual prevejo muito regozijo [3o de setembro de 1829] (Hodges e Hummel, 2002, p. 63). ${ }^{5}$

Nas páginas do seu diário, Harriett Low transmite a imagem de uma sociedade profundamente dividida em função das nacionalidades e das afinidades linguísticas (portugueses e anglófonos) mas também das religiões (católicos e protestantes). Nos primeiros meses da sua estadia, as interações com o mundo chinês são quase inexistentes ou limitam-se a algumas apreciações gerais sobre o povo chinês. $\mathrm{O}$ diário de Harriett Low parece fazer eco às representações pictóricas de Macau, comuns no século XVIII e início do século XIX. Como o analisou Patrick Conner, a península estreita de Macau é então geralmente representada como um enclave dentro de um território chinês cuja representação pictórica se reduz a umas sombras ameaçadoras em segundo-plano (Conner, 2009). Essas representações veiculadas por textos e imagens correspondem em grande parte a um modo de percepção geral da China no mundo ocidental, caracterizada por um ponto de vista holístico onde uma simples observação ou descrição transmite uma ideia geral sobre a China e o povo chinês, considerados no seu conjunto (SPENCE, 1998).

5 "Macao from the sea looks beautiful, with some most romantic spots. We arrived there about ten o'clock, took sedan chairs and went to our house, which we liked the looks of very much. The streets of Macao are narrow and irregular, but we have a garden in which I anticipate much pleasure [September 30, 1829].” 
Mas o diário de Harriett Low registra fatos mais concretos, pequenos acontecimentos e incidentes, descritos com tanto mais pormenores quanto eles venham romper com a monotonia da vida cotidiana. Mais uma vez, é através dos relatos diretos desses "fatos" e "eventos" que podemos entrever o que muda com a difusão de práticas que podemos associar a uma visão lúdica da cidade e dos espaços urbanos. Em vários momentos do seu diário, Harriette Low relata por exemplo passeios no Campo, um trilho que leva até à colina do Convento da Guia, no limite da cidade portuguesa.

Fomos ao Campo, um lugar lindo. O Campo fica a alguma distância fora da cidade, entre duas colinas altas, com o mar a bater-lhe de lado. Subi uma das colinas, que é muito elevada, e ao olhar em volta, encontrei a minha companhia a uma grande distância mais abaixo. Eles não tinham acompanhado os meus passos precipitados, mas mão me arrependi. Era um local perfeito e eu vou lá voltar [27 de outubro de 1829] (Hodges \& Hummel, 2002, p. 75). ${ }^{6}$

Ao longo desses relatos, a jovem americana realça a importância de ver e de desfrutar da paisagem. A repetição, na prática e no texto, do passeio redefine os limites do espaço urbano, aqui definido como espaço de convívio. Esse trilho é cada vez mais frequentado e torna-se um lugar de encontro entre membros da comunidade anglófona.

Fui até o Campo. Parei para falar com a Sra Daniell - estava sentada na sua cadeira com os filhos brincando à sua volta. O atraente papá participava inteiramente nas suas cabriolas inocentes. Foi a imagem mais bonita que alguma vez vi [12 de setembro de 1832] (Hodges \& Hummel, 2002, p. 438).7

Uma parte do Campo serve de terreno de cricket para a comunidade inglesa (LAMAS, 2006, p. 35). Mas esta zona da cidade tornou-se também um espaço privilegiado de contato com a população chinesa que frequentava esse lugar. Esta

6 "We went to the Campo, a beautiful place. The Campo is out of the town some way, is between two high hills, and the sea washing up on side. I ascended one of the hills, which is very high, and on looking round, found my party at great distance below. They had not followed my rash steps, but I was not sorry. It was a perfect spot and I shall try it again [October 27, 1829]." Citado também por Lamas (2006, p. 34-35).

7 "Went out to the Campo. Stopped to speak to Mrs. Daniell - she was sitting in her chair with her children playing round her. The handsome papa was entering fully into their innocent gambols. It was prettier than any picture I ever saw [September 12, 1832]." Citado também por Lamas (2006, p. 34-35). 
dimensão é, por exemplo, visível num episódio onde Harriett Low comenta os hábitos das mulheres chinesas, ficando admirada pelo tamanho dos seus sapatos. "Parece incrível que possam usar tais coisas, mas eu vi-os assim tão pequenos no Campo [02 de novembro de 1833]" (Hodges \& Hummel, 2002, p. 649). ${ }^{8}$

Esses relatos dão a imagem de um lugar mais acolhedor, onde os intercâmbios entre populações de diferentes origens sociais ou culturais são limitados, estritamente enquadrados, mas tornados possíveis pela intermediação do uso recreativo do espaço.

O segundo texto que transmite a ideia de fragmentação do espaço urbano é da autoria de um jornalista português, Carlos José Caldeira, que chegou ao Cantão em novembro de 1850, depois de algumas semanas passadas em Macau (CALDEIRA, 1997). Estamos num período particularmente tenso das relações entre ocidentais e chineses, entre as duas Guerras do Ópio. Carlos José Caldeira não entrou na cidade de Cantão. Ele ficou sobretudo nos subúrbios, nomeadamente na zona das feitorias, descritas como um enclave europeu, no meio do mundo chinês.

As dez horas da noite ancoramos em frente das feitorias europeias em Cantão, no meio de uma multidão de embarcações que atulhavam o rio (....). Era original e curioso o espectáculo de ver estes milhares de embarcações todas iluminadas, e cheias de gente fazendo confusa vozearia na estranha língua chinesa (CALDEIRA, 1997, p. 108).

No relato desta visita, a cidade chinesa é descrita como um amontoado misterioso, rodeado de muralhas e que pode rapidamente tornar-se ameaçador para os europeus. O próprio caráter "urbano" - ou seja "civilizado" - da cidade chinesa é às vezes refutado. Carlos José Caldeira insiste no contraste entre os mundos urbanos chinês e europeu, separados por uma fronteira física - a muralha que cerca a cidade velha de Cantão - mas também por uma oposição de morfologia, padrões e usos. Na margem do rio, onde os europeus construíram habitações "há um bonito jardim ou passeio público no gosto inglês, bem entretido, e que tem no centro uma capela protestante, pequena, mas de elegante estilo" (CALDEIRA, 1997, p. 108). O contraste entre espaços europeus e chineses corresponde também a uma oposição entre ruas nomeadas e sítios sem nome. Durante a sua estadia em Cantão, Carlos José Figueira está particularmente interessado em duas ruas.

8 "It seems incredible that they can wear such things, but I have seen them as small upon the Campo [November 2, 1833]." 
As ruas Old China Street e New China Street atraem logo a atenção do viajante. São as únicas de regular largura que se encontram neste subúrbio de Cantão, ornadas de lojas onde se vêem todos os milagres da indústria, da paciência e do gênio chinês. Enquanto aqui estive nem um só dia deixei de as visitar, e sempre achava novo pasto à minha curiosidade, e novas tentações em dano da minha minguada bolsa. Fora destas ruas tudo o mais é um labirinto de imundas e estreitíssimas ruas, ou antes corredores tapados em parte com esteiras, pejados de uma multidão de populaça, de homem carregados, e de cadeirinhas de condução, que fazem verdadeiramente incômodo e perigoso passear por elas um estrangeiro (CAldeira, 1997, p. 109).

Old China Street e New China Street são ruas afamadas do Cantão da primeira metade do século XIX. Nessa altura, essas ruas, cuja atividade estava essencialmente ligada à presença dos ocidentais, foram objeto de inúmeras representações em pinturas e desenhos, na tradição do "chinese export art" (Conner, 2009, p. 78-83). Eram representadas e utilizadas como lugares de sociabilidade e de recreação (Downs, 2014). Esses espaços correspondiam a um ponto de equilíbrio feliz entre duas conceções da vida urbana. De um lado, os visitantes desfrutam do aspeto exótico e "tipicamente" chinês dessas ruas, do outro, apreciam a proximidade morfológica e funcional como uma ideia "ocidental" do mundo urbano.

\section{NOVOS VIAJANTES E NOVOS OLHARES SOBRE MACAU E CANTÃO NA SEGUNDA METADE DO SÉCULO XIX}

A partir dos anos 1850, os propósitos das viagens no sul da China começam a mudar (ChANG, 2010). Os objetivos comerciais, políticos ou informativos deixam de ser o principal motivo revindicado pelos viajantes. The Canton Chinese, or the American's Sojourn in the Celestial Empire publicado em 1849 pelo americano Osmond Tiffany Jr. marca uma inflexão nos relatos e nas posições assumidas pelos viajantes ocidentais. Num curto prefácio, este comerciante de Baltimore explicita as suas intenções: proporcionar uma observação direta e real da cidade. A viagem não tem nenhum propósito, a não ser visitar e conhecer Cantão e o povo cantonês. Com o seu relato, Osmond Tiffany Jr. quer partilhar uma simples experiência.

Este livro não foi escrito como uma história dos chineses, ou como um ensaio elaborado sobre essa grande nação (...). Ansioso por estudar, tanto quanto pudesse, o aspecto, as maneiras, os costumes, os hábitos e as hierarquias da vida chinesa, decidi entrar em contato real com as pessoas, em vez de permanecer nas hongs 
e obter toda a informação nos inúmeros livros que tinham sido escritos sobre os Celestiais. Com este espírito, dia após dia, vagueei pelas ruas, entrei em todo o tipo de lojas, passei muito tempo no rio densamente povoado e travei conhecimento, tanto quanto me foi possível, com os vários tipos de habitantes (TiffaNY JR., 1849, p. vii). ${ }^{9}$

No final do século XIX, a China integra pouco a pouco os circuitos turísticos internacionais. Assistimos à publicação dos primeiros guias em língua inglesa, que se focam essencialmente em Cantão, Hong Kong (fundada em 1842) e Pequim ${ }^{10}$. Esses primeiros guias difundem dois tipos de discurso. Primeiro, Cantão é geralmente apresentada como a cidade chinesa típica, diferente de Hong Kong e Xangai. Segundo, esses guias identificam e localizam, de uma maneira precisa, com mapas e itinerários, os espaços e os lugares que devem ser considerados como turísticos. No caso de Cantão, essa "cidade turística" não corresponde à cidade velha de Cantão mas, principalmente, às zonas mais periféricas frequentadas pelos ocidentais. No início dos anos 186o, depois da destruição das feitorias, os ocidentais instalam-se um pouco mais a oeste, na ilha de Shameen. As concessões britânicas e francesas de Shameen vão rapidamente tornar-se uma das principais atrações turísticas de Cantão, a par da cidade nova, fora das muralhas, onde se concentram alguns templos tradicionais mas também a Catedral, edificada com a ajuda pessoal do imperador francês Napoleão III e inspirada na Basílica Sainte Clotilde de Paris. A "cidade turística" - a dos guias em papel - constrói-se à margem ou em oposição à "cidade do cotidiano": duas cidades que teriam a sua própria geografia, territorialidade e história. No caso de Cantão, essa distinção corresponde a uma oposição entre "cidade chinesa" e "cidade ocidental".

Os guias do Dr. Kerr, várias vezes reeditados nas últimas décadas do século XIX, oferecem no entanto uma imagem mais complexa da cidade. Esses guias são os primeiros a dar uma descrição completa da cidade, incluída a cidade velha (KERR, 1884). Dr. Kerr tem um conhecimento íntimo de Cantão e da China, como o atesta o uso dos caracteres chineses para descrever os lugares e os modos de vida que os turistas estão convidados a descobrir. Esses guias são também relativamente

9 "This book has not been written as a history of the Chinese, or as an elaborate essay on that great nation [...]. Desirous of studying, as far as lay in my power, the aspect, manners, customs, habits, and ranks of Chinese life, I determined to come in actual contact with the people, instead of remaining in the hongs and obtaining all my information form the numerous books which had been written on the Celestials. In this spirit, day after day, I went about the streets, into all kinds of shops, passed much time on the densely peopled river, and made acquaintance, as far as lay in my power, with the various ranks of the inhabitants".

10 Ver: Dennys (1866), Hall (1877), Eastlake (1883), Kerr (1884) e Hurley (1903). 
modernos na sua concepção: indicam itinerários precisos para dois dias de visita, com as pausas para as refeições. Uns anos mais tarde, o plano de Cantão publicado no guia de Hurler (1903) indica a posição das muralhas, o subúrbio da cidade (a ilha de Shameen) e a cidade nova com a sua Catedral. Os itinerários dos passeios sugeridos por esse guia reforçam esta separação entre, de um lado, uma centralidade geográfica e histórica e, do outro, a centralidade turística. Esses itinerários começam na zona ocidental e não penetram na cidade antiga, convidando o turista a privilegiar a descoberta das zonas periféricas.

A análise de relatos de viagem vem enriquecer e complexificar essa ideia de segmentação desses mundos urbanos. O último relato que vou evocar é sobre Cantão, uns anos mais tarde, em 1877. Trata-se da correspondência de Mrs. Gray, uma inglesa de Liverpool que viajou durante 18 meses na China e fez uma longa estadia de 14 meses em Cantão, durante a qual se correspondeu com a mãe (GRAY, 1880). Neste caso, temos claramente em mão o relato de uma viagem de natureza turística. Vários indícios vão neste sentido. Antes de chegar a Cantão, Mrs. Gray atravessou o Atlântico e faz um longo périplo pelos Estados Unidos - Nova Iorque, Niagara Falls, Chicago, Salt Lake City, San Francisco, etc. - percorrendo a maior parte dos sítios já selecionados e inventariados nos guias turísticos americanos (SCHAFFER, 2001). Por outro lado, a palavra turista aparece na correspondência. Mrs. Gray qualifica de "turista" um europeu de passagem por Cantão que vai visitar a cidade na companhia de Henry Gray, o marido de Mrs. Gray (Gray, 188o, p. 235) ${ }^{11}$. O turista é sempre o outro, mas Mrs. Gray vivia claramente num mundo onde o turismo já era assimilado a um modo comum de viajar.

Mas o que é interessante na correspondência de Mrs. Gray é a transformação que se opera na relação com o outro (os chineses). Esta transformação é particularmente visível em três situações: quando Mrs. Gray assiste a festas ou cerimônias religiosas; na experimentação, desejada ou forçada, de novos pratos e produtos alimentares; na circulação na rua e no espaço público. Nessas três situações, a relação - às vezes o confronto, tão importantes são as diferenças - entre o olhar ou a sensibilidade do viajante (Mrs. Gray) e os estilos de vida da comunidade local (chinesa) é facilitada ou mediada pela prática turística.

A noção de "exotismo" está obviamente sempre presente nesta correspondência. As particularidades dos hábitos alimentares ou do espaço público são vistas

11 John Henry Gray foi um dos primeiros especialistas ocidentais da história do direito e dos costumes chineses. Publicou, nomeadamente: China: A History of the Laws, Manners, and Customs of the People (1878). 
com empatia mesmo quando colidem com os modos de estar ou as percepções "ocidentais".

Nesta cidade pratica-se a mais maravilhosa economia de espaço (...). Mesmo nas ruas estreitas há barracas em todos os cantos e recantos disponíveis, e é difícil para as nossas cadeiras passarem. Exige uma boa dose de gestão, e uma grande quantidade de ruído por parte dos carregadores de cadeiras, quando duas cadeiras se encontram e têm de passar uma pela outra (GrAY, 1880, p. 37). ${ }^{12}$

Mrs. Gray não se afasta muito da "cidade dos guias". A sua descrição da "beautiful French cathedral" (GRAY, 1880, p. 235) atesta a prevalência do olhar ocidental sobre a cidade. No entanto, ela pode questionar a funcionalidade da rua como via de comunicação sem negar a própria "urbanidade” deste espaço.

\section{CONCLUSÕES}

Neste estudo exploratório, propus abordar a história do turismo em Macau e Cantão, analisando situações e práticas plasmadas pelo contexto social e cultural local. Nas últimas décadas do século XIX, a figura do turista torna-se uma presença mais habitual nas ruas de Cantão e Macau. As correspondências e os relatos de viagem, redigidos a partir do final dos anos 1850 dão conta da transformação das intenções e das experiências dos viajantes. No meio dos comentários gerais sobre os pequenos acontecimentos da vida cotidiana e as heranças da presença ocidental, surgem relatos mais detalhados das emoções ou entusiasmos suscitados pelas excursões e os contatos com um mundo chinês, às vezes idealizado. A partir dos anos 1870, alguns visitantes, tal como Mrs. Gray, assumem mais diretamente um "olhar turístico" e situam claramente a sua experiência de viagem na continuidade das práticas turísticas que se difundiram na Europa e na América do Norte desde o final dos anos 1830.

Ao longo do século XIX, as descrições de Macau e Cantão impregnam-se pouco a pouco de uma visão lúdica e turística da cidade moderna, seguindo um modelo já amplamente difundido no mundo ocidental contemporâneo. No entanto, este processo não pode ser lido como o simples resultado da difusão linear de um modelo de vida urbana correspondente às aspirações da burguesa das cidades

12 "There is the most marvellous economy of space practised in this city [...]. Even in the narrow streets there are stalls in all available nooks and corners, and it is difficult for our chairs to get along. It requires a good deal of management, and a great deal of noise on the part of the chair coolies, when two chairs meet and have to pass each other". 
europeias e da Nova Inglaterra. As vivências e situações locais narradas pelos viajantes permitem entrever processos mais complexos, onde as práticas de lazer e de turismo surgem como a forma mais comum de configuração e reconfiguração de um mundo urbano colonial fragmentado.

Através da difusão dessas práticas e usos turísticos é o próprio caráter urbano dessas cidades que é reconhecido. No entanto, a distinção entre a "cidade turística" e a "cidade do cotidiano" continua a ser herdeira de uma longa história das formas de ocupação do espaço e das relações conflituais entre os mundos ocidental e chinês.

\section{REFERÊNCIAS BIBLIOGRÁFICAS}

Bertho LaVEnir, Catherine. La Roue et le stylo. Comment nous sommes devenus touristes. Paris: Odile Jacob, 1999.

Bickers, Robert. Shanghailanders: The Formation and Identity of the British Settler Community in Shanghai 1843-1937. Past and Present, 159, p. 161-211, 1998.

Caldeira, Carlos José. Macau em 1850. Crónica de Viagem. Lisboa: Quetzal Editores, 1997. Chang, Elizabeth H. (Org.) British Travel Writing from China, 1798-19o1, 5 vols. London: Pickering \& Chatto, 2010.

Cocks, Catherine. Doing the Town. The rise of urban Tourism in the United States, $1850-$ 1915. Berkeley: University of California Press, 2001.

Conner, Patrick. The Hong of Canton. Western merchants in south China 1700-190o, as seen in Chinese export paintings. London: English Art Books, 2009.

Dennys, N. B. "Notes for Tourists in the North of China" (1866). In: Chang, Elizabeth H. British Travel Writing from China, 1798-1901. Vol. 3. London: Pickering \& Chatto, 2010, p. 1-50.

DiкоттER, Frank. Exotic Commodities. Modern Objects and Everyday Life in China. New York: Columbia Universty Press, 2006.

Downs, Jacques M. The Golden Ghetto. The American Commercial Community and the Shaping of American China Policy - 1784-1844. Hong Kong: Hong Kong University Press, 2014.

EASTLAKe, F. Warrington. A guide to Hongkong: with a short account of Canton \& Macao, and embracing many chapters of interest relating to the Far East. Hong Kong: W. Brewer Bookseller, 1883.

EDwards, Randle. "The Old Canton System of Foreign Trade”. In: Li, Victor H., Law and Politics in China's Foreign Trade. Seattle: University of Washington Press, 1977, 360-378.

GraY, Mrs. Fourteen months in Canton. London: Macmillan and Co., 1880. 
Hall, E. Hepple. The Picturesque Tourist. A Handy Guide Round the World. For the Use of All Travellers Between Europe, America, Australia. India. China and Japan. New York: American New Company, 1877.

Henriot, Christian. Cities and Urban Societies in China in the Nineteenth and Twentieth Centuries: A Review Essay in Western Literature. Newsletter for Modern Chinese History, 21, p. 151-175, 1996.

Henriot, Christian e Zu'An, Zheng. "Les Divisions de la ville à Shanghai (XIXe - XXe siècles)". In : Topalov, Christian (Dir.) Les divisions de la ville. Paris : UNESCO/ MSH, p. 157-189, 2002.

Hodges, Nan P. \& Hummel, Arthur W. (Org.) Lights and Shadows of a Macao Life. The Journal of Harriett Low, Travelling Spinster. Woodinville: History Bank, 2 vols., 2002.

Hsü, Immanuel C. Y. The Rise of Modern China. New York: Oxford University Press, 1983. HurLey, R. C. The Tourist's Guide to Canton, the West River and Macao. Hong Kong: Hong Kong Printing Press, 1903.

KERR, John Glasgow. The Canton guide complied by Dr. Kerr. Hong Kong: Kelly \& Walsh/ Canton: A.S. Watson \& Co., 1884.

Lamas, Rosmarie W. N. Everything in Style. Harriett Low's Macau. Hong Kong: Hong Kong University Press, 2006.

Lussault, Michel. “Le tourisme, un genre commun”. In: Duhamel, Philipe; Knafou, Rémy. Mondes urbains du tourisme. Paris: Belin, 2007, p. 241-245.

Morse, H. B. The Chronicle of The East India Company Trading to China, 1865-1834. Taipei: Ch'eng-Wen Publishing Company, 1966.

Oliveira, João Carlos. “Sociedade e Cultura”. In: Marques, A. H. de Oliveira. História dos

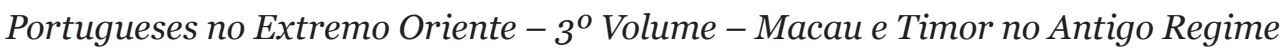
à Republica. Lisboa: Fundação Oriente, 2000.

PugA, Rogério Miguel. Macau e Timor em 1829 - o diário e os desenhos inéditos de Lucy Cleveland. Revista da Fundação Oriente, 18, p. 3-33, 2007. Interpreting Macau through the Journals of Harriett Low and Rebecca Chase Kinsman. Journal of Sino-Western Cultural Studies, 1, p. 156-167, 2008.

SCHAFFer, Marguerite S. See America First. Tourism and National Identity, 1880-1940. Washington and London: Smithsonian Institution Press, 2001.

Spence, Jonathan D. The Chan's Great Continent. China in Western Minds. New York: Norton \& Company, 1998.

SpoDE, Hasso. La recherche historique sur le tourisme. Vers une nouvelle approche. Mondes du Tourisme, 2, p. 4-18, 2010. 
Stоск, Mathis e Lucas, Lépold. La Double Révolution Urbaine du Tourisme. Espaces et Sociétés, 3, 151, p. 15-30, 2012.

The CANTon Register, vol. 19, nº 16 , Tuesday, April 19 th 1836.

Tiffany JR., Osmond. The Canton Chinese or the American's Sojourn in The Celestial Empire. Boston \& Cambridge: James Munroe and Company, 1849.

Urbain, Jean-Didier. L'Idiot du voyage. Histoires de touristes. Paris: Petite Bibliothèque Payot, 2002.

Van Dyke, Paul A. (Org.) Americans and Macao: Trade, Smuggling and Diplomacy on the South China Coast. Hong Kong: Hong Kong University Press, 2012.

Recebido para publicação em: 02/11/2016. Aceito para publicação em: 19/11/2016. 